\title{
Moist Exposed Burn Ointment Effectiveness for Capecitabine Associated Grade II and III Hand Foot Syndrome on Stage III Colonic
}

\author{
Budhi Ida Bagus ${ }^{1}{ }^{\oplus}$, Nunik Agustriani ${ }^{2}$, Rieva Ermawan $^{3}$, Suwardi $^{4}$, Amru Sungkar $^{5}$, Ikhdin R. Saadhi $^{6}$ \\ ${ }^{1}$ Department of Surgery, Sebelas Maret University, Surakarta, Indonesia; ${ }^{2}$ Department of Pediatric Surgery, Sebelas Maret \\ University, Surakarta, Indonesia; ${ }^{3}$ Department of Orthopaedic and Traumatology Surgery, Sebelas Maret University, Surakarta, \\ Indonesia; ${ }^{4}$ Department of Pediatric Surgery, Moewardi General Hospital, Surakarta, Indonesia; ${ }^{5}$ Department of Plastic Surgery, \\ Moewardi General Hospital, Surakarta, Indonesia; ${ }^{6}$ Department of Surgery, Moewardi General Hospital, Surakarta, Indonesia
}

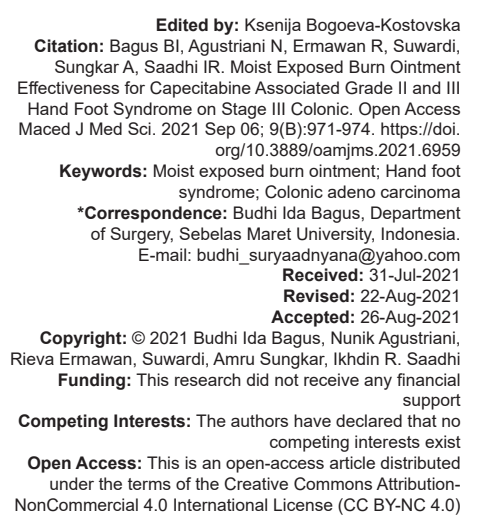

Introduction

Oral chemotherapeutic agents play an important role in the management of many different types of cancer; and it is likely that the use of these drugs will continue to grow. The use of 5 -fluorouracil (5-FU) has been an integral part of many cytotoxic regimens for the treatment of malignant disease over the past four decades. Oral fluoropyrimidine is also called capecitabine; and it has been shown to be effective against colon cancer with a disease-free survival that is at least equivalent to that of fluorouracil-plus-leucovorin treatment [1].

Hand-foot syndrome (HFS) is a wellestablished cutaneous adverse event of certain chemotherapeutic agents, mainly capecitabine, continuously infused 5-FU, docetaxel, and pegylated liposomal doxorubicin. Erythema, dysesthesia, pain, cracking, and desquamation located on palms and soles are the most characteristic manifestations. Although HFS is a reversible and non-life-threatening clinical condition, it can often affect patient's quality of life (QoL) significantly, hence necessitating therapeutic modifications or even treatment discontinuation [2].

HFS, also known as palmoplantar erythrodysesthesia, is a common adverse effect of the fluoropyrimidine chemotherapy agent capecitabine. HFS of any grade is reported to affect $43-71 \%$ of patients. Although not life-threatening, it can have adverse effects on the QoL and daily living activities of a patient. Sometimes the dose interruptions and reductions required after observation of HFS can also impact on dose intensity and treatment outcomes [2], [3].

Oral chemotherapeutic agents play an important role in the management of many different types of cancer. The use of 5-FU has been an integral part of many cytotoxic regimens for the treatment of malignant disease over the past four decades. Oral fluoropyrimidine is also called capecitabine and it has been shown to be effective against colon cancer with a disease-free survival that is at least equivalent to that combination of fluorouracil-plus-leucovorin treatment [1], [2], [3]. 


\section{Methods}

This is a prospective preliminary study on stage III of colorectal cancer patients whose already treat with surgical resection of the primary tumor and followed by adjuvant oral chemotherapy using Capecitabine twice daily with 3 weeks interval and for 6 months period of time. The study has been conducted at the Surgery Department of Moewardi General Hospital, Indonesia from January until June 2021. All patients with already confirmed with colorectal adenocarcinoma will be included in the study. The exclusion criteria are the patient with previous history of chemotherapy before. The presence of clinical sign of symptoms of stage II and III of HFS will be treated with topical moist exposed burn ointment twice daily until the symptoms relieved. The clinical parameter of this study is the improvement of HFS during therapy, the chemotherapy interruption, and dose modification will be reported.

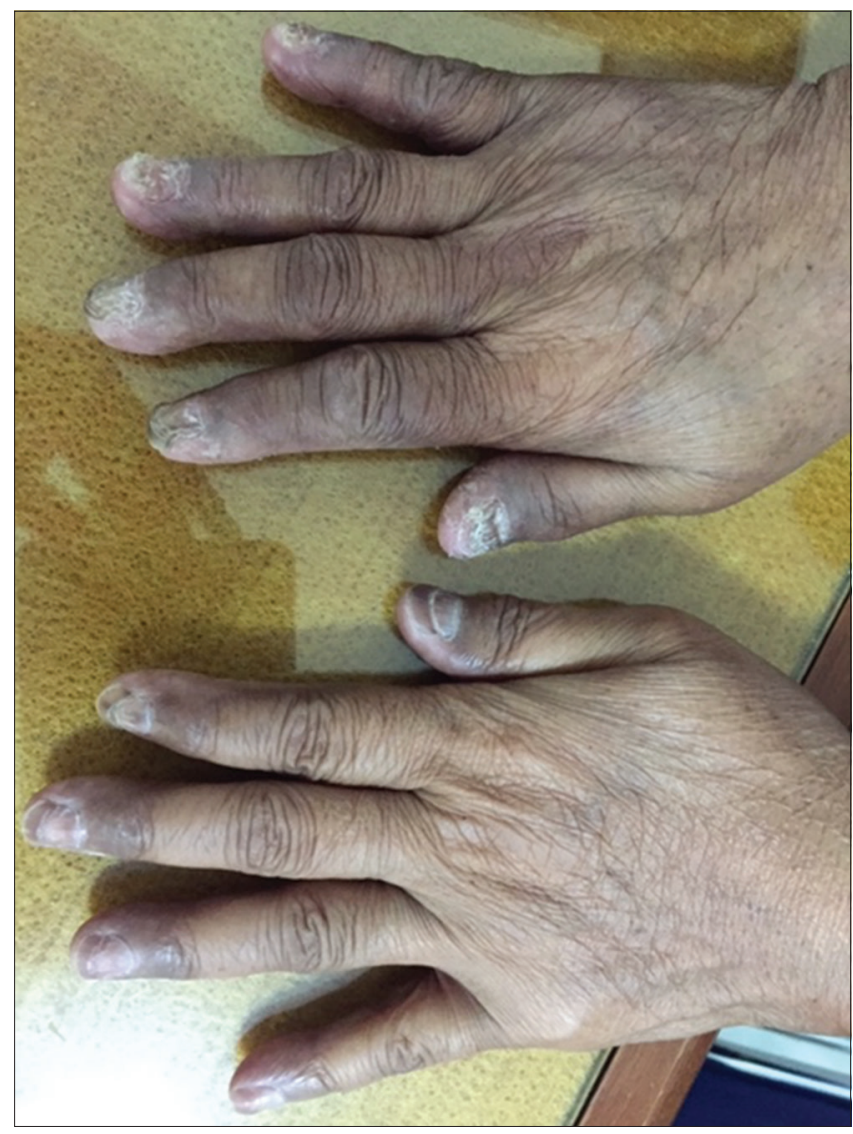

Figure 1. HFS grade III

\section{Results}

Eight cases of Grade II and III HFS have been reported, two patients were Grade III HFS and the others were Grade II. These symptoms occurred after
2 until 3 months after capecitabine administration for locally advanced (stage III) colonic adenocarcinoma. Topical moist exposed burn ointment (MEBO) was used twice a day for 3 months, pain reduction was achieved from the visual analog score (VAS) 5 till 6 to become VAS 1 till 2, with no capecitabine dose interruption and reduction during chemotherapy period. The patients had grade III of HFS during capecitabine therapy on 3 months after initial treatment, capecitabine doses could be maintained and have not interrupted the chemotherapy cycle until remission of those HFS (as seen on Figures 1 and 2).

\section{Discussion}

MEBO is a traditional Chinese medicine burn ointment that has been a USA patented formulation. It has an important role on promote chronic ischemia and neurogenic healing by topical use. This topical agent could be applied on hands and foot for twice daily with various duration. In this study, we applied the MEBO for 3 months to evaluated the clinical response after treatment. Many studies reported the mechanism of MEBO, it could improved the microcirculation of the tissue, participate in neurovascularization of the wound

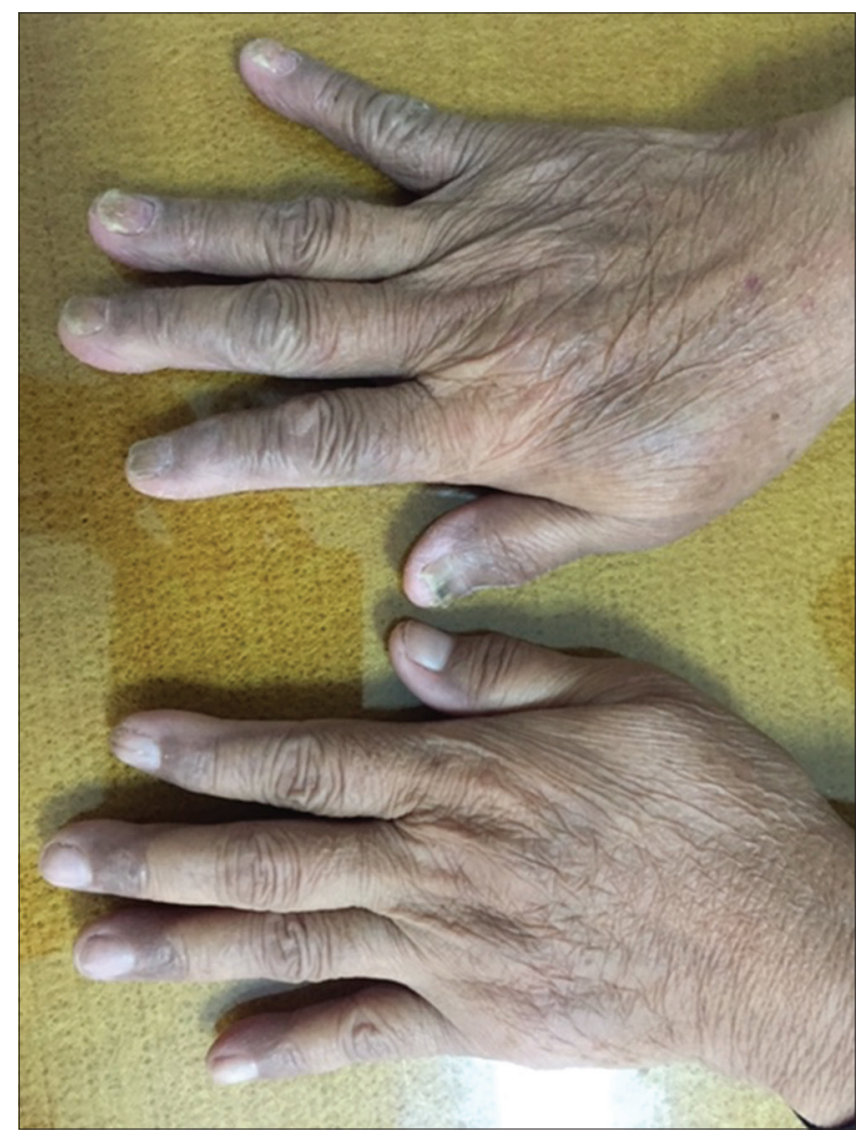

Figure 2. After MEBO administration 
and epithelial regeneration. The earlier clinical usage is for local the treatment of burn injury and ulcer including diabetic ulcer [4].

Early recognition, patient education, and supportive measures are considered as the key elements in the management of HFS. Up to date, treatment interruption and dose intensity reduction are the mainstay of HFS management. Many topical formulations and systemic treatment regimens have been proposed, with cyclooxygenase (COX-2) inhibitors being the most promising agents. Nevertheless, large prospective randomized controlled trials are needed in order to agree on solid, evidence-based treatment algorithms [5].

Capecitabine, an oral prodrug of 5-FU, inhibits DNA synthesis and has received FDA approval for the treatment of metastatic colorectal and breast cancers. HFS is a serious dose-limiting toxicity and the most frequently reported side effect of capecitabine. Because of the lack of knowledge about the causative mechanism of HFS, scarce information is available for effective treatment or prevention [5].

The mechanism responsible for HFS is unknown. For patients receiving 5-FU, HFS is dosedependent and it is probably related to the accumulation of the drug in the skin. One theory proposed to explain capecitabine-associated HFS is that specialized skin cells (keratinocytes) might have upgraded levels of the enzyme thymidine phosphorylase. Another theory suggests that capecitabine may be eliminated by the eccrine system (sweat secretion), and HFS is caused by an unknown mechanism related to the increased number of eccrine glands present in the hands and feet [3], [4], [6].

Several physiological and pharmacological mechanisms have been investigated, such as COX inflammatory-type reaction, accumulation of capecitabine metabolites, and enzymes and transporters involved in the metabolism and absorption. Although current studies describe the possible mechanisms of HFS induced by capecitabine, much remains to be determined. It appears from this scientific evidence that additional study is needed to determine the effect of skin-mediated metabolism in the possible mechanism of HFS induced by capecitabine [7]

Capecitabine is taken in the outpatient setting; it is difficult to monitor treatment compliance and to detect adverse events when compared to the IV chemotherapeutic agents. HFS is a major adverse event that can interfere with the general activities of daily living; therefore, intensive management and care by medical personnel are necessary to treat HFS [6], [8].

The HFS was managed by monitoring the side effects and the medication. In addition, the patients were warned to take special care of their affected areas. They applied skin emollient and skin barrier cream. For the cases with Grade 1 HFS, the treatment continued using the original dose with the application of a skin barrier cream and MEBO. For Grade 2 HFS, the original dose was maintained with application of MEBO [4], [7], [9], [10].

\section{Conclusion}

MEBO was an effective treatment option in managing HFS, better option in reducing the pain without interrupting the capecitabine doses.

\section{References}

1. Twelves C, Wong A, Nowacki MP, Abt M, Burris H $3^{\text {rd }}$, Carrato A et al. Capecitabine as adjuvant treatment for stage III colon cancer. N Engl J Med. 2005;352(26):2696-704. https://doi. org/10.1056/nejmoa043116

PMid:15987918

2. Ota M, Tatsumi K, Suwa $\mathrm{H}$, Watanabe J, Watanabe K, Osada $\mathrm{S}$, et al. The effect of pyridoxine for prevention of handfoot syndrome in colorectal cancer patients with adjuvant chemotherapy using capecitabine: A randomized study. Hepatogastroenterology. 2014;61(132):1008-13.

PMid:26158157

3. Yap YS, Kwok LL, Syn N, Chay WY, Chia JW, Tham CK, et al Predictors of hand-foot syndrome and pyridoxine for prevention of capecitabine-induced hand-foot syndrome: A randomized clinical trial. JAMA Oncol. 2017;3(11): 1538-45. https://doi. org/10.1001/jamaoncol.2017.1269

PMid:28715540

4. Zheng A, Ma H, Liu X, Huang Q, Li Z, Wang L, Zeng N, Wu B Effects of moist exposed burn therapy and ointment (MEBT/ MEBO) on the autophagy mTOR signalling pathway in diabetic ulcer wounds. Pharm Biol. 2020;58(1):124-30. https://doi. org/10.1080/13880209.2019.1711430

PMid:31967912

5. Kang YK, Lee SS, Yoon DH, Lee SY, Chun YJ, Kim MS, et al Pyridoxine is not effective to prevent hand-foot syndrome associated with capecitabine therapy: Results of a randomized, double-blind, placebo-controlled study. J Clin Oncol. 2010;28(24):3824-9. https://doi.org/10.1200/jco.2010.29.1807 PMid:20625131

6. Azuma Y, Hata K, Sai K, Udagawa R, Hirakawa A, Tohkin M, et al. Significant association between hand-foot syndrome and efficacy of capecitabine in patients with metastatic breast cancer. Biol Pharm Bull. 2012;35(5):717-24. https://doi.org/10.1248/ bpb.35.717

PMid:22687407

7. Lou Y, Wang Q, Zheng J, Hu H, Liu L, Hong D, et al. Possible pathways of capecitabine-induced hand-foot syndrome. Chem Res Toxicol. 2016;29(10):1591-601. https://doi.org/10.1021/ acs.chemrestox.6b00215 PMid:27631426

8. Son HS, Lee WY, Lee WS, Yun SH, Chun HK. Compliance and effective management of the hand-foot syndrome in 
colon cancer patients receiving capecitabine as adjuvant chemotherapy. Yonsei Med J. 2009;50(6):796-802. https://doi. org/10.3349/ymj.2009.50.6.796

PMid:20046420

9. Nagore E, Insa A, Sanmartín O. Antineoplastic therapyinduced palmar plantar erythrodysesthesia ("hand-foot") syndrome. Incidence, recognition and management. Am J Clin Dermatol. 2000;1(4):225-34. https://doi. org/10.2165/00128071-200001040-00004

PMid: 11702367

10. Cassidy J, Twelves C, Van Cutsem E, Hoff P, Bajetta E, Boyer M, et al. First-line oral capecitabine therapy in metastatic colorectal cancer: A favorable safety profile compared with intra venous 5-fluorouracil/leucovorin. Ann Oncol. 2002;13(4):566-75. https:// doi.org/10.1093/annonc/mdf089

PMid: 12056707 